\title{
Sylvie Germain. Regards croisés sur "Immensités", sous la direction de Mariska Koopman-Thurlings
}

\section{Elisa Bricco}

\section{Q OpenEdition}

1 Journals

\section{Edizione digitale}

URL: http://journals.openedition.org/studifrancesi/7726

DOI: $10.4000 /$ studifrancesi.7726

ISSN: 2421-5856

\section{Editore}

Rosenberg \& Sellier

\section{Edizione cartacea}

Data di pubblicazione: 1 décembre 2009

Paginazione: 671-672

ISSN: 0039-2944

\section{Notizia bibliografica digitale}

Elisa Bricco, «Sylvie Germain. Regards croisés sur "Immensités", sous la direction de Mariska KoopmanThurlings», Studi Francesi [Online], 159 (LIII | III) | 2009, online dal 30 novembre 2015, consultato il 09 janvier 2021. URL: http://journals.openedition.org/studifrancesi/7726 ; DOI: https://doi.org/10.4000/ studifrancesi.7726

Questo documento è stato generato automaticamente il 9 janvier 2021.

\section{(c)}

Studi Francesi è distribuita con Licenza Creative Commons Attribuzione - Non commerciale - Non opere derivate 4.0 Internazionale. 


\title{
Sylvie Germain. Regards croisés sur "Immensités", sous la direction de Mariska Koopman-Thurlings
}

\author{
Elisa Bricco
}

\section{NOTIZIA}

Sylvie Germain. Regards croisés sur "Immensités", sous la direction de Mariska KOOPMANTHURLINGS, Paris, L’Harmattan, 2008 («Critiques Littéraires»), pp. 210.

1 Il volume raccoglie dodici studi incentrati sul romanzo Immensités, pubblicato nel 1995 da Sylvie Germain, autrice contemporanea che ha ormai ottenuto ampi riconoscimenti dai lettori e dalla critica (tre monografie sull'insieme della sua opera, cinque convegni, un centinaio di articoli universitari).

«Toute écriture est un palimpseste», diceva all'inizio della sua carriera S. Germain in un'intervista per esprimere la stratificazione delle esperienze personali e collettive che nutrivano le sue opere, e il volume appare proprio come un palinsesto in cui gli approcci critici e le letture s'innestano sul testo oggetto di studio mettendone a nudo la grande ricchezza e le molteplici interpretazioni possibili. La rete esegetica che viene a formarsi sul testo d'Immensités presenta saggi che mettono in rilievo aspetti tematici del romanzo, altri che s'incentrano sulle tecniche narrative e infine sulla ricerca metafisica soggiacente.

Il percorso esistenziale del protagonista Prokop Poupa, che lo conduce dalla presa di coscienza dolorosa dell'inanità di ogni sforzo per migliorare la propria vita alla pacificazione finale e a una sorta di riconciliazione intima, è al centro dei contributi di Bénedicte LANOT, Fable du deuil et morale du renoncement (pp. 11-33) e di Marie-Hélène BOBLET, «Immensité en notre finiture»: histoire et humanité (pp. 35-45). Le caratteristiche stilistiche del romanzo e soprattutto la compresenza di diverse tipologie narrative consentono alla scrittrice di variare $\mathrm{i}$ toni e di affrontare il racconto da latitudini 
differenti. Il racconto Les Trois coffrets che Prokop narra al figlio, è al centro dell'analisi omonima di Laurent DEMANZE, (pp. 47-60) il quale illustra come l'inserzione di questo testo permetta a $\mathrm{S}$. Germain di «mettre en scène la confrontation de deux modes narratifs: l'oralité des sociétés traditionnelles et la solitude des êtres modernes» (p. 59). Anche Jutta FORTIN, in Entre petitesse et immensité: fragmentation et détails poignants (pp. 61-78), affronta l'estrema frammentazione narrativa del testo, ma sotto una luce diversa perché situa questa caratteristica nell'estetica postmoderna. Cécile NARJoux ( L'Extrêmement petit appelait à l'infiniment grand»: lyrisme et ironie dans “Immensités”, pp. 79-96) affronta la tematica, primaria nella poetica germainiana, della duplicità costitutiva della natura umana rilevando gli elementi testuali che contribuiscono a crearla: le trasgressioni enunciative e narratologiche esprimono questa scissione intima del protagonista che, uomo tra gli uomini, incarna la crisi contemporanea dell'identità. Lo studio dei molteplici riferimenti intertestuali e intratestuali porta Toby GARFITT (Les Écholalies de Sylvie Germain, pp. 97-106) a dimostrare come la reminiscenza sia alla base della ricerca della propria identità da parte del protagonista.

4 La profonda ricerca metafisica è l'oggetto dei saggi di Etty MULDER in Musique divine et musique terrestre (pp. 107-119) che si sofferma sugli elementi musicali eterogenei del testo per mettere in evidenza il sottofondo che conduce alla "conversione" dell'eroe. Nathalie Roflens (L'Acquiescement de Prokop, pp. 122-139) ripercorre le tappe della trasformazione di Prokop in una prospettiva che lo conduce dal religioso al sacro. La prospettiva teologica è alla base della riflessione di Toine VAN DEN HOOGEN, Théo-logie et le contrepoint de la réalité quotidienne (pp. 142-160), il quale spiega che «l'histoire de Prokop est celle de l'absence de Dieu» (p. 157). Il nulla metafisico impersonato da Prokop è studiato anche da Isabelle DOTAN ( $\mathrm{Du}$ "vide" au "vide". Une révision de la pensée existentialiste, pp. 161-174) che sceglie il confronto con la prospettiva esistenzialista. L'ultimo contributo, della curatrice del volume (Temps et mémoire, pp. 175-189), opera una sintesi delle potenzialità del testo perché affronta la tematica del tempo e della memoria a cui è strettamente connesso. Chiude il volume un contributo di Sylvie GERMAIN, L'Esprit de la pierre. Le chef-d'œuvre de Braun en Bohême (pp. 194-205). 